\title{
LETTER
}

\section{JR-3, a LIL-enriched GSJ rock reference sample}

\author{
HIKARI KAMIOKA \\ Geological Survey of Japan, Tsukuba, Ibaraki 305, Japan \\ (Received June 21, 1994; Accepted August 5, 1994)
}

\begin{abstract}
Nineteen elements were measured for a new GSJ rock reference sample, JR-3, by instrumental neutron activation analysis. It is found that JR-3 is much more abundant in large ion lithophiles such as rubidium, the rare earth elements, hafnium, tantalum, thorium and uranium than any other GSJ rock reference materials. No significant heterogeneity of the sample powder is detected for the amount of $60 \mathrm{mg}$ level. Thus, JR-3 is especially useful as an analytical standard for those elements.
\end{abstract}

\section{INTRODUCTION}

The Geological Survey of Japan (GSJ) has issued new series of rock reference samples, JR-3 (peralkaline rhyolite), JGb-2 (leucogabbro) and JH1 (pyroxene hornblendite) (Terashima et al., 1993), in addition to older "igneous rock series" and "sedimentary rock series." These new reference samples are characterized by the distinct enrichment of certain elements, i.e., the rare earth elements (REEs) for JR-3, aluminum for JGb-2, magnesium and calcium for $\mathrm{JH}-1$. Thus, they are designed especially for the use as standard materials for above elements in various kinds of instrumental analyses including instrumental neutron activation analysis (INAA), X-ray fluorescence (XRF), inductively coupled plasma-atomic emission spectrometry (ICP-AES) and so on.

Terashima et al. (1993) reported the analytical results of some major and minor elements for the new reference samples but their REE contents were not given. This paper presents analytical data of nineteen elements including REEs for JR-3 measured by INAA.

\section{Analytical Method}

Nineteen aliquots, about $60 \mathrm{mg}$ each, of JR-3 (split 6, position 72) were sealed in quartz tubes ( $3 \mathrm{~mm}$ diameter) as described by Tanaka et al. (1988). Neutron irradiation was carried out at the JRR-4 reactor of the Japan Atomic Energy Research Institute, Tokai. Samples were irradiated with JB-1 as a standard material in T pipe of the reactor for forty minutes in a thermal neutron flux of $8 \times 10^{13} \mathrm{~cm}^{-2} \mathrm{~s}^{-1}$.

After seven days' cooling, $\gamma$-ray spectra of the samples were measured using a hyperpure germanium detector (ORTEC GEM20180) and a multi-channel analyzer (SEIKO EG\&G 7800-8A2) with an automatic sample changer (Tanaka $e t$ al., 1988). The second measurement was done after additional twenty days. Integration times for the first and second measurements were $11000 \mathrm{sec}-$ onds and 20000 seconds, respectively.

According to half lives of the nuclides of interest, better data were selected from either of the two sets of measurements or the sets of data were averaged. For lanthanum and samarium, results of 
only the first measurement were chosen to avoid interferences from ${ }^{140} \mathrm{Ba}$ and ${ }^{239} \mathrm{Pu}$, respectively. The interferences arise from uranium and increase rapidly with time.

\section{RESUlts AND Discussion}

The average elemental concentrations of nineteen JR-3 samples are shown in Table 1 together with the coefficients of variation $(1 \sigma)$ for the nineteen values. Approximate $\gamma$-ray counting errors $(1 \sigma)$ for each element are also given in the table in percentage.

Terashima et al. (1993) also analyzed sodium, iron, cobalt, rubidium and cesium by atomic absorption spectrometry and flame emission spectrometry. Data in Table 1 show no significant difference from their results.

\section{Interferences by fissiogenic nuclides}

For neutron activation analysis, neutron induced fission of ${ }^{235} \mathrm{U}$ is known to cause interferences on some elements such as light REEs and

Table 1. Analytical results for JR-3

\begin{tabular}{lccc}
\hline Element & Concentration & C.V. $(\%)^{2}$ & $\begin{array}{l}\text { Counting } \\
\text { error }(\%)^{3}\end{array}$ \\
\hline $\mathrm{Na}(\%)$ & 3.57 & 1.4 & 0.5 \\
$\mathrm{Sc}(\mathrm{ppm})$ & 0.458 & 2.1 & 1 \\
$\mathrm{Fe}(\%)$ & 3.32 & 1.3 & 0.3 \\
$\mathrm{Co}(\mathrm{ppm})$ & 1.13 & 4.0 & 3 \\
$\mathrm{Rb}(\mathrm{ppm})$ & 461 & 2.8 & 5 \\
$\mathrm{Cs}(\mathrm{ppm})$ & 0.845 & 4.5 & 6 \\
$\mathrm{Ba}(\mathrm{ppm})$ & 221 & 7.9 & 6 \\
$\mathrm{La}(\mathrm{ppm})$ & 178 & 1.6 & 0.5 \\
$\mathrm{Ce}(\mathrm{ppm})$ & 331 & 1.8 & 0.4 \\
$\mathrm{Nd}(\mathrm{ppm})$ & 107 & 3.5 & 10 \\
$\mathrm{Sm}(\mathrm{ppm})$ & 22.5 & 2.9 & 0.3 \\
$\mathrm{Eu}(\mathrm{ppm})$ & 0.463 & 3.7 & 3 \\
$\mathrm{~Tb}(\mathrm{ppm})$ & 4.15 & 2.8 & 7 \\
$\mathrm{Yb}(\mathrm{ppm})$ & 22.0 & 2.1 & 3 \\
$\mathrm{Lu}(\mathrm{ppm})$ & 2.88 & 2.1 & 3 \\
$\mathrm{Hf}(\mathrm{ppm})$ & 40.5 & 2.0 & 1 \\
$\mathrm{Ta}(\mathrm{ppm})$ & 38.9 & 3.1 & 2 \\
$\mathrm{Th}(\mathrm{ppm})$ & 112 & 2.5 & 0.4 \\
$\mathrm{U}$ (ppm) & 22.0 & 3.6 & 6 \\
\hline
\end{tabular}

${ }^{I}$ Average of nineteen samples.

${ }^{2}$ Coefficient of variation $(l \sigma)$ for the nineteen values.

${ }^{3}$ Approximate $\gamma$-ray counting error $(I \sigma)$.
Table 2. ${ }^{235} \mathrm{U}$ fission interferences

\begin{tabular}{lllll}
\hline & $\mathrm{La}$ & $\mathrm{Ce}$ & $\mathrm{Nd}$ & $\mathrm{Zr}$ \\
\hline $\begin{array}{l}{ }^{235} \mathrm{U} \text { fission } \\
\text { interference }^{1}\end{array}$ & $0.029^{2}$ & 0.28 & 0.25 & 11 \\
\hline
\end{tabular}

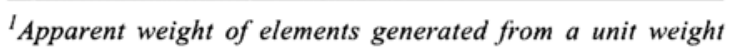
of uranium.

${ }^{2}$ The value at 7 days after irradiation in T pipe for $40 \mathrm{~min}$ utes.

zirconium (Potts, 1987; Kawabe et al., 1994), because the fission yields are relatively high for the nuclides of mass numbers around 100 and 140 . For this work, the following fission products are possible to affect the analytical results; ${ }^{140} \mathrm{Ba}$ (disintegrates to ${ }^{140} \mathrm{La}$ ), ${ }^{141} \mathrm{Ce},{ }^{147} \mathrm{Nd}$ and ${ }^{95} \mathrm{Zr}$. The amounts of these nuclides formed by the fission of uranium were calculated just as described by Kawabe et al. (1994) and listed in Table 2 as the apparent weight of elements generated from a unit weight of uranium. For the calculation, cadmium ratio of 4.0 with $\mathrm{Au}$ monitor was used to estimate thermal/resonance neutron flux ratio and the nuclear data such as thermal neutron cross sections, resonance integrals and fission yields were taken from Walker et al. (1977) and Murakami et al. (1982).

All the data for lanthanum, cerium and neodymium given in Table 1 are corrected for the interferences described above using the values in Table 2. Calculated contributions of fission interferences relative to the corrected values for lanthanum, cerium and neodymium are $0.4 \%, 2 \%$ and $5 \%$, respectively. These are as small as the analytical errors.

Data for zirconium are not given in Table 1 because of the uncertainty which arises from much larger fission interference compared to those for REEs. Using the value in Table 2, zirconium content in JR-3 is estimated to be about 1420 ppm which is by far the highest among the GSJ reference samples. The contribution of the interference is $17 \%$ relative to the estimated content.

\section{Homogeneity of the sample powder}

Some minor elements tend to be distributed 
unevenly in a sample powder by concentrating in certain accessory minerals. This heterogeneity of a sample powder is known to cause so called sampling error for analytical results when sampling amount is not large enough. For example, Kamioka and Tanaka (1989) reported the variations of $10 \% \sim 20 \%(1 \sigma)$ for the analytical results of REEs, chromium, hafnium and thorium in GSJ rock reference samples, JG-1 and JG-1a, with the sampling amount of $70 \mathrm{mg} \sim 80 \mathrm{mg}$. Above variations are much larger than $\gamma$-ray counting errors of the elements and are attributed to the sampling error.

As for the result of JR-3, coefficients of variations are within a few percent $(1 \sigma)$ for most of the elements including REEs, hafnium and thorium. Much smaller sampling errors for JR-3 than the case for JG-1 and JG-1a may result from the larger abundance and smaller grain size of accessory minerals containing REEs etc. in JR-3. Kamioka and Tanaka (1989) made a theoretical consideration on sampling error based on binomial and Poisson statistics. They showed that a larger abundance of a phase containing an element of interest and a smaller grain size of the phase lead to more homogeneous distribution of the element, resulting in a smaller sampling error for a given sample amount. Though Ishihara et al. (1990) suggested the existence of zircon, xenotime and a light REE enriched mineral from microscopic and SEM studies, REE bearing phases in JR-3 could not be identified. This means that the REE bearing phases are abundant but their sizes are too small to be identified.

For JR-3, it is concluded that about $60 \mathrm{mg}$ of the sample powder is homogeneous enough and well represents the chemical composition of JR-3 for the elements given in Table 1.

\section{Characteristics of the chemical composition of $J R-3$}

Figure 1 shows the crustal-abundance-normalized compositions of JR-3 and some other GSJ rock reference samples. It is clear that JR-3 is much more abundant in large ion lithophiles (LIL) such as rubidium, REEs (except europium), hafnium, tantalum, thorium and uranium than any other GSJ rock reference materials. On the other

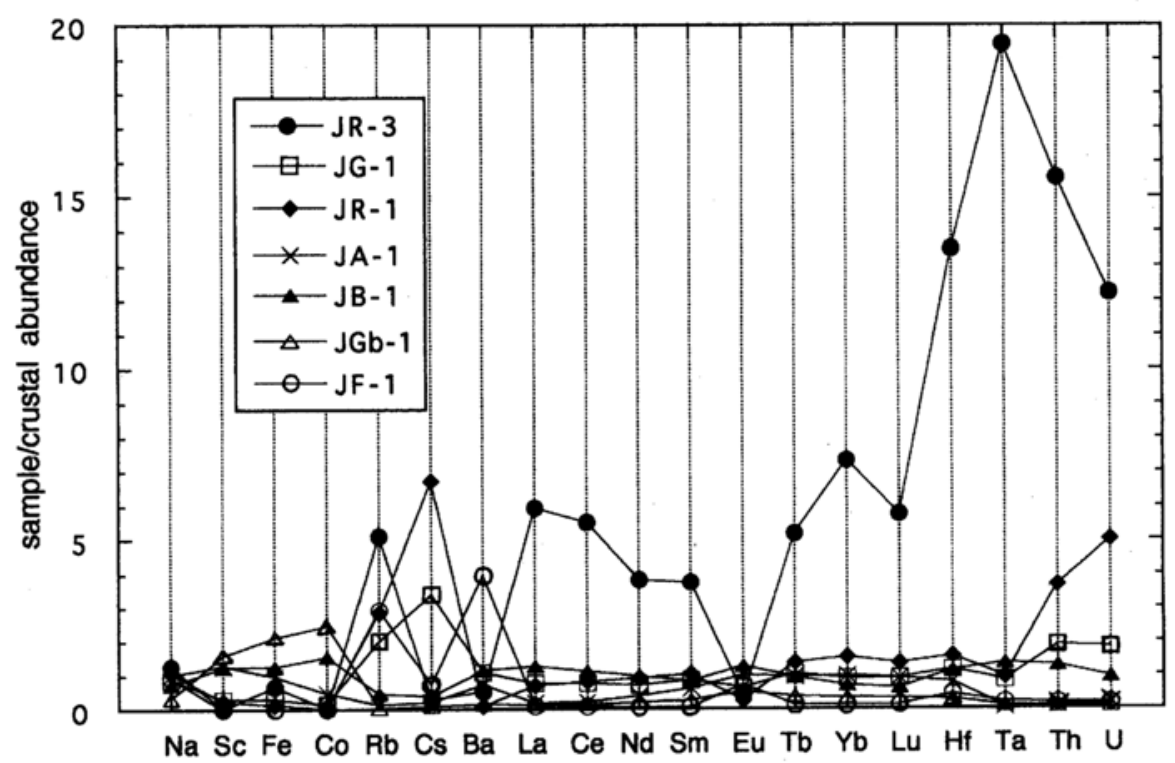

Fig. 1. Crustal-abundance-normalized compositions of GSJ reference samples. Crustal abundances and chemical compositions of GSJ reference samples (except JR-3) are taken from Mason (1966) and Ando et al. (1989), respectively. 


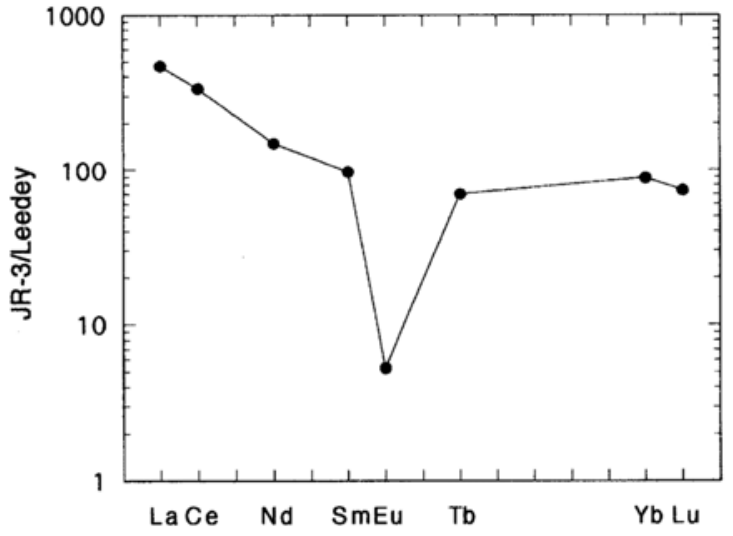

Fig. 2. Chondrite-normalized REE abundance pattern of $J R-3$.

hand, concentrations of scandium and cobalt are low compared to other reference samples. Chondrite-normalized REE abundance pattern (Fig. 2) is similar to those of other GSJ rhyolite reference samples, JR-1 and JR-2 (Itoh et al., 1992), except for the absolute abundances.

Above characteristics ensure the usefulness of JR-3 as an analytical standard of LIL in various kinds of instrumental analyses. For example, the low concentrations of scandium and cobalt relative to LIL give an advantage for the analyses of LIL by INAA, because, for $\gamma$-ray spectra of samples, the strong and high energy $(>1 \mathrm{MeV})$ photo peaks of scandium and cobalt result in the enhanced background of lower energy side by Compton scatter, causing interferences on the photo peaks of many elements including LIL. For XRF, the high concentrations of LIL such as rubidium and zirconium are also a big advantage for the construction of calibration lines.

Acknowledgments-I am thankful to Dr. Y. Matsuhisa of GSJ and an anonymous reviewer for their critical reading of the manuscript and constructive comments. I also thank Dr. S. Togashi of GSJ for a useful discussion on instrumental analyses.

\section{REFERENCES}

Ando, A., Kamioka, H., Terashima, S. and Itoh, S. (1989) 1988 values for GSJ rock reference samples, "Igneous rock series." Geochem. J. 23, 143-148.

Ishihara, S., Tanaka, T., Terashima, S., Togashi, S., Murao, S. and Kamioka, H. (1990) Peralkaline rhyolite dikes at the Cape Ashizuri: A new type of REE and rare metal mineral resources. Min. Geol. 40, 107-115.

Itoh, S., Terashima, S., Imai, N., Kamioka, H., Mita, N. and Ando, A. (1992) 1992 compilation of analytical data for rare-earth elements, scandium, yttrium, zirconium and hafnium in twenty-six GSJ reference samples. Bull. Geol. Surv. Jpn. 43, 659733.

Kamioka, H. and Tanaka, T. (1989) The problems in the analyses of geological materials by INAA-An examination of the analytical results of GSJ rock reference samples. J. Geol. Soc. Jpn. 95, 835-850 (in Japanese with English abstract).

Kawabe, I., Inoue, T. and Kitamura, S. (1994) Comparison of REE analyses of GSJ carbonate reference rocks by ICP-AES and INAA: Fission and spectral interferences in INAA determination of REE in geochemical samples with high U/REE ratios. Geochem. J. 28, 19-29.

Mason, B. (1966) Principles of Geochemistry. John Wiley \& Sons, New York, 329 pp.

Murakami, Y. et al. (eds.) (1982) Nuclear Data Book. Chijin-shokan, Tokyo, 429 pp. (in Japanese).

Potts, P. J. (1987) A Handbook of Silicate Rock Analysis. Blackie, Glasgow, 622 pp.

Tanaka, T., Kamioka, H. and Yamanaka, K. (1988) A fully automated $\gamma$-ray counting and data processing system for INAA and analysis of rock reference samples. Bull. Geol. Surv. Jpn. 39, 537-557 (in Japanese with English abstract).

Terashima, S., Itoh, S., Ujiie, M., Kamioka, H., Tanaka, T. and Hattori, H. (1993) Three new GSJ rock reference samples: Rhyolite JR-3, gabbro JGb-2 and hornblendite JH-1. Geost. Newsl. 17, 1-4.

Walker, F. W., Kirouac, G. J. and Rourke, F. M. (1977) Chart of the Nuclides. twelfth edition, General Electric Company, San Jose, 52 pp. 